\title{
APREHENDER A INTERPRETAR: COMPETENCIA DEL MUNDO MEDIÁTICO
}

\section{LEARNING TO INTERPRET: COMPETENCE OF THE MEDIA WORLD}

\author{
Frank Soto Ocampo ${ }^{1}$ \\ Corporación Universitaria Minuto de Dios \\ (Uniminuto), Buga, Colombia.
}

\section{RESUMEN}

Se presentan los hallazgos, resultados y conclusiones de la investigación sobre cómo las competencias de interpretación de textos e imágenes inciden en actividades académicas para ser un profesional competitivo. El objetivo consistió en explicar el estado de la formación sobre competencias de interpretación de textos e imágenes de los estudiantes de Comunicación Social. Se aplicó la metodología etnográfica que generó significación descubriendo los conocimientos y cogniciones de los estudiantes y profesores a través de cuestionarios, entrevistas y pruebas, además, del estudio de algunos cursos y la metodología del programa. Es una investigación @cualitativa basada en el análisis de los currículos, conocimientos de los sujetos y de documentos relacionados con la interpretación teniendo como base categorías

$\overline{1}$ Facultad de ciencias humanas y sociales, Programa Comunicación Social, Corporación Universitaria Minuto de Dios (Uniminuto), Buga, Colombia. Correo electrónico: fsotoocampo@uniminuto.edu.co. Orcid ID: ttps://orcid. org/0000-0002-4491-5443 tríadicas a priori. El resultado evidenció falencias en los procesos y los procesamientos de interpretación de los conocimientos para poder aprehender a aprehenderlos. La discusión lleva a preguntar si los estudiantes universitarios son competentes para entender, comprender e interpretar las narrativas auditivas y visuales. La conclusión indicó que para afrontar el estado de la formación en interpretación, es necesario aplicar el concepto teórico Cognición comunicativa interpretativa construido y sustentando en esta investigación.

\section{PALABRAS CLAVE}

Comunicación, competencias, cognición, entender, comprender, interpretar, aprehender.

\section{ABSTRACT}

The findings, results and conclusions of the research on how the competences of interpretation of texts and images affect academic activities to be a competitive professional are presented. The objective 
consisted of explaining the state of the training on competences of interpretation of texts and images of the students of Social Communication. The ethnographic methodology that generated significance was applied by discovering the knowledge and cognitions of the students and teachers through questionnaires, interviews and tests, in addition to the study of some courses and the methodology of the program. It is a qualitative research based on the analysis of the curricula, knowledge of the subjects and documents related to interpretation based on a priori triadic categories. The result revealed shortcomings in the processes and processing of interpretation of knowledge to be able to apprehend to apprehend them. The discussion leads to the question of whether university students are competent to understand, comprehend and interpret auditory and visual narratives. The conclusion indicated that to face the state of interpretation training, it is necessary to apply the theoretical concept Interpretative Communicative Cognition supporting this research.

\section{KEYWORDS}

Communication, competences, cognition, understand, comprehend, interpret, apprehend.

\section{INTRODUCCIÓN}

Por sus características, el perfil profesional y laboral de los programas de Comunicación Social deberían formar a los estudiantes en las competencias del entender, del comprender y del interpretar creativamente, constructivamente y críticamente los textos y las imágenes. Según Cassany (2004), si el estudiante no discrimina, no evalúa la confiabilidad, no examina la coherencia, no identifica la ideología, no devela la intención, etc., de los documentos que ofrecen los motores de búsqueda, no es competente para realizar una apropiación crítica (p.9). Aflora la necesidad de crear nuevos procesos cognitivos en el estudiante como parte de la enseñanza aprendizaje, para lo cual se propone el concepto teórico denominado Cognición Comunicativa Interpretativa que permite dinamizar el desarrollo comunicacional de los universitarios hoy mediados.

Es necesario conocer la etimología de la palabra cognición, que según el portal Significados (s.f) dice que "Así, la cognición es una facultad propia del ser vivo que le permite registrar e interpretar la información que recibe a través de la experiencia, la percepción y la subjetividad. (párr.2), lo que lleva a plantear que no son solo representaciones (imágenes virtuales en el cerebro) de la cosa (entiéndase como objetos físicos, fenómenos sociales, objetos sociales y fenómenos físicos), sino que genera algo más allá denominado interpretación (inferencias sobre lo que se está aprehendiendo); pero la cognición en esta investigación no solo se queda en este punto, sino que se relaciona con lo cognitivo.

La enseñanza - aprendizaje continúa centrándose en lograr que los estudiantes entiendan y comprendan los conocimientos; son muchos los estudios sobre estos aspectos, mientras que la interpretación de los conocimientos al parecer no ha tenido tanto énfasis. Acevedo, Martínez y Román (2014) afirman que "La mayoría de las investigaciones, plantean que los estudiantes a la hora de iniciar sus estudios universitarios carecen de: estrategias de estudio, conocimientos generales, conciencia de los procesos intelectuales, identidad en el desempeño académico, análisis de las tareas académicas asignaturas, [...]" (p.127). La enseñanza - aprendizaje de la educación media no debe continuar afectando las competencias académicas de los estudiantes y profesionales, por lo cual, es necesario que los educandos y el modelo cuenten con procesos y procedimientos de formación que les permitan superar las debilidades y deficiencias que afrontan en materia de interpretación. 
Las debilidades en las competencias de interpretación se reflejan en la forma y el fondo como los estudiantes buscan las respuestas en los textos, en las imágenes o en las mixturas de éstos, ya que los educandos demandan que en lo explícito, denotado, significado, literal, etc., se manifiesten, situación que típicamente no es así. Gordillo y Flórez (2009) manifiestan, "Los estudiantes reconocen la estructura base del texto $y$, por ende, realizan copias literales con el propósito de responder a preguntas que no demandan mayor construcción y análisis discursivo" (p.100). Es necesario que los educandos diferencien los procesos y los procedimientos que se deben desarrollar en la lectura para alcanzar un nivel adecuado de interpretación, ya que, si en la educación presencial afrontan problemas en este aspecto, la situación se complica mucho en más en la digital.

Leer no solo dinamiza los conocimientos que tienen los estudiantes sobre asuntos académicos, sino que detona las competencias para construir su pensamiento complejo y abstracto, ya que les da los insumos para afrontar las realidades y verdades desde la congruencia de los saberes. De acuerdo a Montaño (2010), "leer es, básicamente, saber comprender y, sobre todo, saber interpretar, o sea saber llegar a establecer nuestras propias opiniones, formuladas como valoraciones y juicios. Leer es participar en un proceso activo de recepción" (como se citó en Muñoz et al., 2013, p.779). La lectura no consiste solamente en el significado de los contenidos, y no solo es decodificar textos o un acto del entender. La lectura es la contextualización social, cultural, política, económica, histórica, global, etc., del texto, como producto de un proceso de inmersión: es interpretación.

La educación hoy no debería tratarse de conocer (usar) herramientas para aprender informaciones y conocimientos con los mapas conceptuales, los cuadros comparativos, los resúmenes, etc., de lo que se trata es de aprehender (apropiar) como procesar informaciones y conocimientos, porque situaciones como la pluralidad, la instantaneidad y la falsedad sustentadas en diferentes soportes (e-book, video $4 \mathrm{~K}$, streaming, podcast, etc.), formatos (multimedia, hipermedia, transmedia, playground, etc.) y narradores (youtubers, influencers, bloguers, etc.) demandan que los estudiantes sean competentes para develar la trama mediática.

Paraalcanzar loque en esta investigación se denomina "cognición comunicativa interpretativa” es necesario preguntarse si la lectura también es aplicable y válida para las imágenes, ya que la mayoría de las veces se propone leer la imagen, pero podría cuestionarse preguntando si el planteamiento debería ser más bien interpretar la imagen. "Observar que las imágenes, expresadas en fotos, diseños, etc., son elementos constituyentes, y no elementos determinantes. Nunca, desde esta perspectiva una imagen, por sí sola, constituiría un texto. Por tanto, las imágenes, sin grafemas, se describen, se observan, se analizan, más nunca se leen" (Almaguer y Peña, 2009, párr. 53). Aunque las imágenes se interpretan desde la lengua (idioma), es decir, desde la palabra escrita $u$ oral, esto no implica que se esté leyendo; lo que se está haciendo es la contextualización social, cultural, política, económica, histórica, global, etc., de la imagen, y como producto de un proceso de inmersión, es interpretación.

Sobre problema se formuló la pregunta: ¿qué conocimientos y cogniciones tienen los estudiantes del programa de Comunicación Social sobre entender, comprender e interpretar los textos, las imágenes y la mixtura de textosimágenes? con el propósito de desarrollar el objetivo general de la presente investigación, que consistió en: explicar el estado de la formación sobre competencias de interpretación de textos e imágenes de los estudiantes de Comunicación Social. 


\section{RESPECTO AL TEXTO}

La construcción de nuevos argumentos debe ser la prioridad al leer el texto, contribuyen al conocimiento académico, porque lo ratifiquen, lo controvierten, lo corroboran, lo cuestionen, lo desvirtúan, etc., especialmente la lectura debe direccionarse a escudriñar la intención del texto, ya que se puede plantear una posición innovadora (diferencialmente valiosa), alineadora a otro(s) autor(es) o contradecir (incluso desacreditando). Cassany (2010), refiere que "[...] al leer no basta con comprender lo que se dice, sino que debemos interpretarlo. Interpretar significa aquí valorar críticamente el texto: [...]. Implica tener respuestas para preguntas como: ¿es cierto?, ¿me fío?, ¿lo pongo en práctica?, ¿estoy de acuerdo?, etc. (p.192). La lectura del texto no debe quedarse en los significados de las palabras, de las oraciones y de las frases, si es eso sucede, se considera que el lector tiene un pensamiento y una acción pasiva respecto al contenido del documento, es decir, consume lo literal del texto.

Las funciones de lenguaje están involucradas con los tipos de textos como parte de las estrategias comunicativas y publicitarias, ya que estos operan como estructuras modeladoras que condicionan la forma como aprehender la realidad y la verdad. Werlich (1975) precisa que "[...] la combinación de la dimensión cognitiva ("modos de abordar la realidad") con la dimensión lingüística ("modos de representar la realidad") reconoce la existencia de cinco tipos textuales básicos que pone en relación con las operaciones cognitivas: descriptiva, narrativa, expositiva, argumentativa, instructiva [...]" (como se citó en Alexopoulou, 2010, párr.43). La diferenciación de las tipologías es la base cognitiva que el lector tiene en el momento de afrontar el texto, pues no se trata de comenzar a realizar consultas, sino de contar con las competencias para interpretar las implicaciones de localizar un texto en una determinada tipología.
$\mathrm{Si}$ las competencias lectoras están cimentadas, la escritura tiene unas bases adecuadas, porque el lector interioriza la tipología, la estructura, las funciones, etc., por lo que se concluye, que es aquella lectura que se hace deconstruyendo profundamente el significado $y$ sentido $y$ construyendo creativamente la significación del texto, más no se refiere, a la consagración conformista de la alienación ni a la aplicación de fórmulas concluyentes. Peñalver (2008) afirma que "[...] no se trata sólo de leer lo escrito, de descifrar lo significado por un significante ya instituido. Ahora la lectura es más bien una escritura. [...] La naturaleza se convierte en libro sólo para aquél que es capaz de escribirlo (p.134). Entonces, la lectura debe ser una nueva escritura de la narración leída, porque los referentes de quien ausculta las informaciones y conocimientos no están en el vacío, sino en la interacción sistémica con lo escrito, donde se involucran los contextos (circunstancias y entornos) internos y externos del texto.

$\mathrm{Si}$ el mundo se interpreta desde la escritura, entonces la contextualización debe ser una prioridad, sin embargo, es necesario que esta se aleje de la coherencia, que se rige por lo significado y se adhiere a lo heredado del texto y contexto, ya que en ese momento la interpretación resulta afectada, porque se realiza y se produce desde los discursos imperantes. Van Dijk (2000), enfatiza que "La mayor parte del discurso se interpreta en contextos sociales. Esto significa que se interpreta junto con una interpretación similar de ese contexto social" (p.156). Lo expresando por el autor ratifica que la mayoría de las interpretaciones se hacen desde el discurso dominante, de moda, del establecido, son alienadas, por lo cual, para poder superar esas situaciones y que se construyan y creen interpretaciones inéditas, es necesario desarrollar procesos y procedimientos cognitivos comunicacionales interpretacionales de congruencia, planteando la investigación 
diversa del texto y del contexto para construir una lectura y una escritura enriquecida y divergente.

\section{RESPECTO A LA IMAGEN}

Es importante recordar en este momento que los primeros vínculos sociales de los seres humanos se establecieron a través de la imagen (símbolos y signos), y que posteriormente mediante la institucionalización de imágenes (signos) como los del abecedario, se pudo contar con códigos comunes geográficos para comunicarse, lo que permitió sustantivar la cosa. Escobar (2016) manifiesta que "[...] la palabra se posiciona también dentro del ámbito de la visualidad y, por tanto, implica que el lector sea también un espectador; y, por su parte, la imagen, actúa en el ámbito de la lectura, exigiéndole a su espectador que sea capaz de convertirse, además, en lector" (p.17). Se establece una confluencia mediática entre el libro, la televisión y la computadora: en todos está presente la palabra escrita u oral con sus representaciones del contexto a través de las imágenes mentales, y entre las dos (palabra imagen), no se distinguen límites.

Las representaciones evocadas por la palabra - imagen o la imagen - palabra no son universales, pero siempre han pretendido serlo, comenzando con la transculturización, pasando por las industrias culturales, hasta la globalización informativa, con muchísimos éxitos comerciales, culturales, políticos y económicos, insertando valores, códigos y creencias propios y foráneos. Según Yuste (2011), "Para comprender la información aportada por una imagen hay que compartir los mismos códigos semióticos y culturales que el público a quien va dirigida, [...] poseer las competencias culturales suficientes sobre la historia y los valores sociales de la cultura de partida [...]" (pp.5-6). Se puede decir que los estudiantes universitarios viven y experimentan un mundo mediático tecnológico sensorial convulsionado e intensificado por textos - imágenes y viceversa, pero si no cuentan con las capacidades y competencias para construir y crear adecuadamente pensamientos y acciones desde sus conocimientos, no pueden alcanzar estadios adecuados en sus procesos de cuestionamiento de la verdad y la realidad.

Una de tantas preguntas que se pueden hacerconrelaciónalaeducaciónes: ¿porquépese a que los seres humanos aprehenden a través de las imágenes mentales (representaciones de la palabra - imagen / imagen - palabra), es decir, el pensamiento y las representaciones se construyen virtualmente; ahora cuando el mundo se vive y se experimenta a través de las imágenes inmateriales (representaciones de la palabra - imagen / imagen - palabra), se insiste por parte de la academia en continuar en un porcentaje casi total trabajando con y desde el texto? Pantoja (2008) puntualiza que "no debemos olvidar que la imagen siempre se ha presentado como ilustración del mensaje escrito, lo que la ha condicionado $y$, al mismo tiempo, ha definido su función" (p.192). Precisamente, los que los profesores pretenden es tratar de llevar las denominadas realidad(es) y verdad(es) al aula física a través de imágenes, al exponer las fotografías de prensa, los documentales, los videos de los medios sociales, etc., como evidencia de lo escrito o expresado; así, esa imagen que no es objetiva será objetivada por la palabra, ya que se declara presente en los hechos y acontecimientos, cosa que no logra el texto. Por lo tanto, los estudiantes deberían ser competentes para interpretarla.

En el cuestionamiento sobre la persistencia de la academia de menospreciar la imagen, es importante tener en cuenta las resistencias a la transformación y el cambio, pero también a los modelos conservadores sobre los cuales operan los sistemas educativos. Sostiene Escobar (2016) que, "[...] es de suma importancia realizar dos aclaraciones: primero, que las imágenes, aunque pertenecen al orden de la visualidad, poseen capacidad de construir discursos verbales; segundo, que las palabras, 
pese a pertenecer al orden de lo verbal, son capaces, a su vez, de construir imágenes" (p.20). Se infiere que las imágenes y las palabras no son excluyentes porque hacen parte de una simbiosis enriquecedora que debe ser interpretada, pero una de las cosas que llama la atención es que las instituciones universitarias están brindando educación virtual sin diseñar metodologías apropiadas para las dinámicas que demandan estos nuevos modelos que tienen un componente robusto de imágenes. Simplemente, han trasladado las metodologías fundamentadas en el texto del aula física a la pantalla con consecuencias graves de calidad.

Es necesario que la educación actualice sus soportes, formatos y narradores para representar y codificar las realidades y verdades, ya que ahora la palabra no es el supremo mediador por antonomasia. Hoy la imagen se apropió de gran parte del espacio que la presentaba como inamovible, debido a que los estudiantes son formados solo para representar a través de textos, lo que les genera un sesgo sobre la percepción de la cosa constituida por las imágenes mentales y producidas. Sartori (2000) resalta que "[...] la televisión invierte la evolución de lo sensible en inteligible y lo convierte en el ictu oculi, en un regreso al puro y simple acto de ver. La televisión produce imágenes y anula los conceptos, y de este modo atrofia nuestra capacidad de abstracción y con ella toda nuestra capacidad de entender (p. 47)". Se concluye que cuando lo sensorial incursiona mediáticamente en el ver y la escucha a través de los sentidos de los consumidores, satisface y resuelve las verdades y realidades mediante las informaciones y los conocimientos subjetivados a los cuales los estudiantes son expuestos, quienes se abruman por la objetividad con la que los hechos son presentados.

Por siguiente, el mediador de la imagen, en este caso la televisión y la internet, tienen consecuencias dramáticas sobre los procesos y los procedimientos de enseñanza aprendizaje.
Por lo tanto, la cognición comunicativa interpretativa, propuesta como concepto en esta investigación resulta pertinente, ya que según lo expresado con relación a cómo se aprehende la imagen, se establece que la educación actual la estudia desde conocimientos que tienen como base signos y los símbolos preestablecidos desde el texto que la limitan y cierran. Sartori (2000) destaca los efectos: "EI obstáculo, durante este largo camino, es que el niño de tres o cuatro años se inicia con la televisión. Por tanto, cuando llega a Internet su interés cognoscitivo no está sensibilizado para la abstracción" (p. 55). Como los estudiantes continúan siendo formados con base en el texto, cuando expresan por escrito $u$ oralmente sus representaciones lo siguen haciendo a través de la palabra, cerrando los significados de las abstracciones. Por lo tanto, cuando los estudiantes enfrentan la imagen, ocurre algo trágico: deben recurrir a la palabra para poder manifestar los contenidos abstractos de esta, que ya vienen malformados por la palabra y los mediadores (familia, educación, prensa, redes sociales, radio y televisión). En consecuencia, como la imagen demanda ser interpretada, solo se pueden alcanzar pertinentes entenderes y comprenderes, en otras palabras, significados y sentidos, pero es excepcional producir significaciones (interpretaciones) académicas pertinentes.

\section{METODOLOGÍA}

Se tomó la determinación de aplicar la observación participativa, ya que es la más acorde a la metodología etnográfica, porque de acuerdo a su fundamento, el investigador (profesor) hace parte de los sujetos investigados, participa de las actividades de éstos y pretende encontrar una explicación sobre lo que investiga. Martínez (2007), plantea que "Estar dentro significa ser parte de la población estudiada y ser parte del problema analizado" (p.75). Lo que facilitó en la investigación poder ahondar en determinadas informaciones y datos, construir 
nuevas estrategias y acciones, y confirmar determinados hallazgos que crearon ciertas divergencias.

El segmento poblacional con el cual se trabajó estuvo conformado por estudiantes y profesores de Comunicación Social, que en interacción académica viven y experimentan las dificultades del aprehender, y constituyen un estudio de caso múltiple, al cual se le aplicaron instrumentos como cuestionarios, entrevistas y pruebas (solo a los educandos) de diferentes índoles. Se hizo un análisis documental sobre algunos currículos y metodologías con base en criterios precisos, que desde la visión de Yin (1988) "Se trata de una "generalización analítica" (utilizar el estudio de caso único o múltiple para ilustrar, representar o generalizar a una teoría)" (como se citó en Martínez, 2006, p.173), por lo cual, la investigación respondió justamente a lo que destaca el autor, ya que se explicaron la forma y el fondo de cómo los investigados percibían el entender, comprender e interpretar en el aprehender, lo cual generó nuevos conocimientos académicos desde los propios protagonistas.

El muestreo fue no probabilístico: primero, se trató de una investigación cualitativa; segundo, se conocieron las particularidades de los investigados; y tercero, no se partió de una hipótesis pese a que existen unos supuestos implícitos. Según Salamanca y Martín-Crespo (2007) "Puesto que lo que buscamos son buenos informantes, es decir, personas informadas, lúcidas, reflexivas y dispuestas a hablar ampliamente con el investigador" (p.2). Esta investigación se abstuvo de hacer pronósticos sobre los hallazgos, resultados y conclusiones, ya que se trataba de indagar y develar los conocimientos que tenían los investigados (estudiantes y profesores) sobre el entender, el comprender y el interpretar.

Para construir las categorías que sirvieron de cimiento a la cognición comunicativa interpretativa, se tuvieron en cuenta las descripciones (propiedades, dimensiones, significados), las relaciones (articulaciones, coherencias, sentidos) y los núcleos (esencias, congruencias, significaciones) que se establecieron sobre los objetivos de la investigación. Sobre le creación y clasificación de estas categóricas, Strauss y Corbin (2002) dicen que "[...] las categorías tienen poder analítico porque poseen el potencial de explicar y predecir. [...] Las categorías son conceptos derivados de los datos, que representan fenómenos" (p.124). Estas permitieron recuperar de la cotidianidad, lo que se excluye como ordinario o bajar desde lo abstracto lo que se estigmatiza como complejo, pero también se tuvo en cuenta el tipo de categorías que se debían diseñar de acuerdo a las necesidades de conocimientos de la investigación.

\section{DESARROLLO}

Con base en el marco referencial y en los objetivos, se construyeron parte de las categorías, mientras que otras emergieron de los cuestionarios y las entrevistas, logrando establecer que los procesos y los procedimientos de conocimiento pasan por la interacción triádica del entender, del comprender y del interpretar. La academia, ni en la primaria, ni en la secundaria, ni en la universidad, desarrolla actividades pedagógicas ni didácticas que sustenten conceptualmente, ni explique transcendentalmente la secuencialidad integral e integradora esencial del aprehender a aprehender en la enseñanza aprendizaje.

Con base en los hallazgos de la metodología etnográfica, se planteó una nueva categoría conceptual cognición comunicativa interpretativa, que tiene como objetivo explicar que la enseñanza aprendizaje en el mundo mediatizado virtualmente demanda la inmersión de los estudiantes en procesos y procedimientos pedagógicos y didácticos, que tengan como objetivo el aprehender a aprehender. 
Visualizando y aplicando la triada del entender, del comprender y del interpretar como un fenómeno mental, donde tiene lugar una pluralidad secuencial de acciones de conocimiento, por lo tanto, no es viable ver la enseñanza aprendizaje como instrumento basado en metodologías (formatos) estándares que determinan cómo debe pensar y hasta dónde debe pensar el estudiante, incluso el profesor, sino en procesos y procesamientos cognitivos comunicativos interpretativos de información y conocimientos. Pirela y Montiel (2007) precisan "La arquitectura de la mente humana se consolida y recompone mediante la interacción con el conocimiento, a través de un proceso de comunicación cognitiva, entendido como proceso de acción mediada, realizado en ambientes formales y no formales de aprendizaje con el propósito de preparar a los sujetos para su incorporación activa en la cibersociedad" (p.2). Con base en Pirela y Montiel, se puede establecer la imbricación entre lo comunicativo y lo cognitivo en el mundo de la internet, donde lo comunicativo no corresponde solamente al compartir la información o el conocimiento a través de un medio, sino esencialmente determinar los soportes, los conceptos, los formatos, los narradores, los signos, los símbolos, los contextos, las interacciones, etc., pertinentes que constituyen y organizan las formas $y$ fondos de los contenidos adecuadamente para cautivar el aprehender; también se puede establecer que lo cognitivo no es una implante metodológico (formato) que establece cómo se deben alcanzar resultados, sino que son procesos y procedimientos pedagógicos y didácticos secuenciales, organizadores y escalonados intrínsecos para aprehender interpretativamente.

Se concluye que el concepto Cognición comunicativa interpretativa está integrado por mediaciones del aprehender a aprehender, porque cuando se dispara el conocimiento, intervienen acciones de pensamiento $y$ mentales que lo hacen posible, y lo que sucede es que el sujeto cognoscente no es consciente de éstas, da por hecho que es competente (espontáneamente) para resolver los problemas académicos aplicando los métodos estandarizados, ya que desconoce cómo aprehender a aprehender. Lo más increíble es que el sistema educativo también da por hecho que es competente, es más le exige que resuelva los problemas sin haberlo preparado para lograrlo, porque supone que aprendió formatos para hacerlo, es decir, promociona e inserta en el estudiante acciones repetitivas y mecánicas de fórmula. Bruner (1964), aclara que "El desarrollo del funcionamiento intelectual del hombre desde la infancia hasta toda la perfección que puede alcanzar está determinado por una serie de avances tecnológicos en el uso de la mente" (como se citó en Schunk, 1997, p.1). Por lo cual, la enseñanza aprendizaje debe actualizarse, ya que las acciones medidoras del sujeto (cibernauta), como del no lugar (cibercultura) y de la educación (ciberformación) han cambiado, mientras el sistema educativo sigue operando con las mimas metodologías de la supremacía del texto en un mundo que trasmutó hacia la imagen, o a la fusión del texto - imagen como mediadores informativos y de conocimientos.

\section{RESULTADOS}

Para poder explorar completamente el concepto teórico Cognición comunicativa interpretativa, la sección de resultados se compone de dos secciones. En la primera, se expone en concepto de la Secuencialidad del Aprehender a Aprehender: Procesos y Procedimientos de la Cognición Comunicativa Interpretativa. En la segunda, este concepto y sus componentes se profundizan mediante un análisis cualitativo y exploratorio. 
SECUENCIALIDAD DEL APREHENDER

A APREHENDER: PROCESOS Y PROCEDIMIENTOS DE LA COGNICIÓN COMUNICATIVA INTERPRETATIVA

En esta investigación se propone un modelo concepto que contiene los tres tipos de procesos y procedimientos de aprehender a aprehender(accionesmediadoras):Investigación mediatizada (análisis comparacionista (entender)), Confrontación sustentada (reflexión conexionista (comprender) y Producción congruente (inferencia contextualizada (interpretación)), con las cuales los estudiantes podrán afrontar la era de la información y del conocimiento con fundamentos pedagógicos y didácticos sobre el cómo aprehender.

Es importante notar la construcción gramatical del concepto: Cognición comunicativa interpretativa, que tiene en primer lugar la cognición, referida a la complejidad de aprehender a conocer; comunicativa, alusiva a las acciones mediadoras en el aprendizaje; e interpretativa, relativa a la creación de visiones innovadoras sobre la realidad; cuyos forman los procesos y los procedimientos del aprehender a aprehender, que se presentan como el resultado de la construcción de categorías a priori validadas en el desarrollo de esta investigación por los sujetos vinculados, tanto estudiantes como profesores.

La secuencialidad del concepto cognición comunicativa interpretativa que organiza los procesos y los procedimientos que deberían ser apropiados por la académica para compartirlos con los estudiantes, incluso los profesores, comienza con el entender. Mediante el entender, se quiere conocer "la cosa," conformado por el representar (imagen), el significado, la pregunta ¿qué codificó el emisor?, la asociación con representaciones (imágenes), el analizar, el denotar y la microestructura (significado); continúa con el comprender, donde es necesario relacionar las partes del conocer la cosa, constituido por el sentido, la pregunta ¿por qué se codificaría ese texto o imagen?, las conexiones coherentes de conocimientos (previos y nuevos), el reflexionar y la macroestructura (sentido). Culmina con el Interpretar, en el cual se crean nuevos conocimientos con base en el conocer la cosa, integrado por el inferir, el significar, la pregunta ¿para qué se codificó el texto o imagen?, la contextualización social, cultural, política, histórica, etc., el connotar, la superestructura (significar o significación). A continuación se presenta la estructura. 
Tabla 1. Secuencialidad del Entender, del Comprender y del Interpretar.

\begin{tabular}{|c|c|c|c|}
\hline & Entender & Comprender & Interpretar \\
\hline & $\begin{array}{l}\text { Significado } \\
\qquad \text { (CIT) }\end{array}$ & $\begin{array}{l}\text { Sentido } \\
\text { (COP) }\end{array}$ & $\begin{array}{c}\text { Significar } \\
\text { (COP) }\end{array}$ \\
\hline & $\begin{array}{c}\text { Representar (Imagen) } \\
\text { (COP) }\end{array}$ & $\begin{array}{l}\text { Imaginar } \\
\text { (COE) }\end{array}$ & $\begin{array}{l}\text { Imaginario } \\
\text { (COE) }\end{array}$ \\
\hline & $\begin{array}{l}\text { ¿Qué codificó el } \\
\text { emisor? } \\
\text { (CIT) }\end{array}$ & $\begin{array}{l}\text { ¿Por qué se codificaría ese } \\
\text { texto o imagen? } \\
(\mathrm{CIT})\end{array}$ & $\begin{array}{c}\text { ¿Para qué se codificó el } \\
\text { texto o la imagen? } \\
\text { (CIT) }\end{array}$ \\
\hline $\begin{array}{l}\text { Secuencialidad } \\
\text { del Aprehender } \\
\text { a Aprehender: }\end{array}$ & $\begin{array}{l}\text { Asociación con } \\
\text { representaciones } \\
\text { (imágenes) }(\mathrm{CIT})\end{array}$ & $\begin{array}{c}\text { Conexiones coherentes de } \\
\text { conocimientos (previos y } \\
\text { nuevos) } \\
\text { (CIT) }\end{array}$ & $\begin{array}{c}\text { Contextualización } \\
\text { social, cultural, política, } \\
\text { histórica, etc. (CIT) }\end{array}$ \\
\hline $\begin{array}{c}\text { Procesos y } \\
\text { Procedimientos }\end{array}$ & $\begin{array}{l}\text { Explicar } \\
\text { (COE) } \\
\end{array}$ & $\begin{array}{l}\text { Proponer } \\
\text { (COE) } \\
\end{array}$ & $\begin{array}{l}\text { Construir } \\
\text { (COE) }\end{array}$ \\
\hline $\begin{array}{l}\text { de la Cognición } \\
\text { Comunicativa } \\
\text { Interpretativa. }\end{array}$ & $\begin{array}{l}\text { Analizar } \\
\text { (COP) } \\
\end{array}$ & $\begin{array}{c}\text { Reflexionar } \\
\text { (COP) } \\
\end{array}$ & $\begin{array}{l}\text { Inferir } \\
(\mathrm{COP}) \\
\end{array}$ \\
\hline & $\begin{array}{c}\text { Denotar } \\
\text { (COP) }\end{array}$ & $\begin{array}{l}\text { Actuar } \\
\text { (COE) }\end{array}$ & $\begin{array}{c}\text { Connotar } \\
\text { (CIT) }\end{array}$ \\
\hline & $\begin{array}{c}\text { Microestructura } \\
\text { (COP) }\end{array}$ & $\begin{array}{c}\text { Macroestructura } \\
\text { (COP) } \\
\end{array}$ & $\begin{array}{c}\text { Superestructura } \\
\text { (COP) } \\
\end{array}$ \\
\hline
\end{tabular}

Fuente: Construcción propia. Los conceptos del Entender, del Comprender y del Interpretar encabezan cada una de las columnas. Las categorías iniciales teóricas (CIT) en gris claro y las categorías originales propias (COP) en gris un poco más oscuro, con las cuales se plantearon los instrumentos y herramientas. Las categorías originales emergentes (COE) en gris más oscuro, que surgieron durante la aplicación de los instrumentos y herramientas.

Con base al concepto de la Secuencialidad del entender, del comprender y del interpretar, y la investigación realizada por medio de la metodología etnográfica, a continuación se profundizan los hallazgos.

La academia como uniformadora y hegemonizadora del conocimiento y la información, propicia que los docentes demanden de los estudiantes interpretaciones iguales o similares a las que ellos hacen, fundamentándose en la respuesta verdadera o correcta que prima los absolutos y las certezas evaluativas. Peñalvier (2008), enfatiza que "En la tradición católica, al texto se le atribuye un sentido polisémico lo que explica la necesidad de una sola interpretación considerada como canónica, la de la institución eclesial" (p.143). Se puede inferir que la autoridad trabaja la interpretación de forma muy similar para custodiar el poder de la palabra, que impresa u oral se visualiza a través del texto; lo mismo ocurre con la imagen, 
donde otro tipo de autoridad, o incluso la misma, salvaguarda la interpretación de los símbolos.

En una aplicación verdadera de la interpretación, se deben tener en cuenta las características sociales, culturales, políticas y económicas de los estudiantes, en el momento de interpretar un texto, una imagen o la mixtura texto - imagen, que necesariamente la afectan, debido a que los estudiantes tienen rasgos demográficos y diferentes y diferenciales; Por ejemplo, las familias de los estudiantes pueden tener una fuerte carga política. Van Dijk (1994) destaca "Se necesita mucho para modificar las ideologías de base una vez están instauradas en nuestro modelo, pues sirven de filtro para explicar cada cosa que se observa, se lee o se escucha; el modelo de ideología es utilizado constantemente en cada acto, [...]" (p.52). Se puede precisar que existen tipos de entender y comprender preestablecidos socialmente, culturalmente, políticamente y económicamente, es decir, que las personas desde esos pesos ideológicos construyen, deconstruyen y distribuyen sus interpretaciones, hecho que no es abordado por el sistema educativo.

Pero hay otra situación que se suma a lo descubierto: cuando simplemente vemos cómo aprehenden los estudiantes, nos damos cuenta que para unos, es más fácil a través de lo visual, para otros por medio de lo auditivo y mientras que algunos por lo táctil, lo que tampoco es tenido en cuenta por parte de la academia, porque el sistema educativo está concebido para estandarizar a través del texto y de la imagen, o de la mixtura texto - imagen, con el objetivo de evitar divergencias y reproducir la estructura política imperante. Macías (2002) dice "Si en su proceso de aprendizaje cada persona aprende de forma distinta, el problema se complicará aún más, pues el sistema educativo suele privilegiar la inteligencia lingüística y lógico-matemática por sobre las demás" (p.36). Esta situación complejiza aún más la enseñanza aprendizaje de los estudiantes, ya que cada educando tiene aprehensiones diferentes y diferenciadas; si imaginemos un aula de clase física o una de tutoría virtual, entonces nos asaltan muchas preguntas, por ejemplo, qué sucede si el docente presenta una película de cine para interpretar determinado tema.

Definitivamente es necesario replantear la enseñanza aprendizaje, sobre todo en un mundo donde la educación está siendo vista desde la comunicación mediático formativa y la tecnología aplicativa resolutiva, debido a la interacción constante entre los componentes mencionados, con varios y diferentes agravantes. Por ejemplo, la comunicación utiliza los medios audiovisuales para apoyar el entender no para detonar la interpretación en los encuentros con los estudiantes, la tecnología establece las plataformas (estándares) dentro de las cuales se debe formar bajo intereses comerciales y académicos, y la educación aún no logra hacer una introspección adecuada para construir con la comunicación y la tecnología productos pedagógicos y didácticos pertinentes. Filmus (2003), manifiesta que "El avance científicotecnológico ha pasado a ser el principal referente para definir tanto lo que va a ser necesario enseñar y aprender en el futuro como qué tipo de instituciones, trabajo pedagógico y tecnologías será el encargado de transmitir los nuevos saberes" (p.18). En consecuencia, podemos plantearnos la siguiente pregunta: ¿Cuáles son las competencias en que la academia debe formar a los estudiantes desde la triada tecnología educación comunicación? De inmediato, aparecen en términos de hoy, categorías como: crítica, innovación, creatividad, debatir, aprender, informática, estrategia, emprendimiento, calidad, interpretar, descubrir, entre otras, todas inmersas y en interacción con el concepto teórico propuesto en esta investigación. La nueva educación más que enseñanza aprendizaje de contenidos debe poner en marcha procesos y procedimientos 
de enseñanza aprendizaje para que los estudiantes aprehendan a aprehender procesos y procedimientos para pensar.

La academia debe considerar que el conocimiento hoy está mediado por la Internet, en donde los estudiantes de la escuela, el colegio y la universidad hacen consultas referenciales y resuelven actividades, es más, existen procesos y procedimientos de enseñanza aprendizaje que se desarrollan parcialmente o totalmente a través de plataformas educativas, lo cual demanda competencias cognitivas diferentes y diferenciadas para aprehender, en donde las interacciones mediáticas con las informaciones y los conocimientos expresados a través del texto - imagen deben optimizar la interpretación. Pirela y Montiel (2007) enfatizan "[...] la acción comunicativa-cognitiva debe promover el aprendizaje que llamamos tecnológicoinformativo, el cual contempla el desarrollo de la actitudes, habilidades y destrezas metacognitivas, habilidades para seleccionar, filtrar, procesar y expresar la información y el conocimiento, [...] (p.79). Aprehender hoy, es ser competente en procesos y procedimientos cognitivos comunicacionales interpretativos para investigar informaciones y conocimientos mediáticos en diferentes soportes, formatos y narradores, cada uno con sus propias e innovadoras formas de representar y codificar, con creativas estrategias para construir mensajes de textos - imágenes, y con elementos sensoriales intencionalmente espectaculares, que contienen códigos, creencias y valores hilvanados con signos para los cuales la educación tradicional no forma.

\section{CONCLUSIONES Y DISCUSIÓN}

El aprehender a aprehender pedagógicamente los procesos y los procedimientos de los conceptos del entender, del comprender y del interpretar ahora es más relevante que nunca, debido a que por la contingencia sanitaria de la pandemia del Covid
19, las universidades que ofrecían educación presencial o las que parcialmente la aplicaban, tomaron decisiones que hoy están siendo evaluadas. Por ejemplo, trasladar a la virtualidad las clases o tutorías como estaban planeadas en los encuentros físicos, comprar los servicios de plataformas virtuales que preestablecen estructuras para las clases o tutorías, contratar asesorías extranjeras de otras universidades a las cuales le funciona un determinado modelo virtual, crear estándares virtuales para las diferentes clases o tutorías que supuestamente son eficientes y acogerse a las sugerencias de formación virtual planteadas por el gobierno nacional, son todas estas situaciones sobre las cuales hay diversidad de manifestaciones. Aún, no existe preocupación a un nivel público, seria, ni ampliamente reconocida por la confluencia de los tres conceptos citados en la educación virtual, ya que a la academia y a los estudiantes les parecen cotidianos y que los manejan con propiedad, sin tener en cuenta que el gran reto radica en cómo lograr que aprehendan a procesar informaciones y conocimientos.

Los estudiantes deberían ser formados para aprehender a afrontar situaciones mediáticas cambiantes, enmarcadas en la incertidumbre, la falsedad, la incongruencia, las interacciones, los conflictos, la exclusión, la usabilidad, la mutabilidad, la diacronía, la simbología, la apropiación, etc. Echeverry (2006), concluye que "Las viejas certezas de la modernidad pierden su significado; se articulan de modos diferentes los territorios, los regímenes políticos y las formas culturales; [...] el imaginario de los individuos y las colectividades, en todo el mundo, se encuentra influido por los medios de comunicación" (p.15); estas situaciones están siendo promovidas y difundidas constantemente mediante la interacción tecnología - comunicación - educación a través de los nuevos medios que construyen y deconstruyen los contextos, circunstancias y entornos, influyendo la educación. Por lo cual, 
urge que los universitarios sean competitivos para cuestionar y criticar innovadoramente, emprendedoramente, tolerantemente y creativamente lo que esté sucediendo en el mundo. De lo contrario, los estudiantes arriesgan a seguir aprendiendo en un mundo abarrotado de desinformación y tergiversación como el de los medios tradicionales.

Para que se eleve el estadio de formación de los estudiantes, se debe propiciar que el aprehender de los universitarios se aleje reflexivamente $\mathrm{e}$ interpretativamente de la forma como ellos fueron educados, es decir, de la usabilidad, la alfabetización, la accesibilidad, la transmisión, la funcionalidad, el informacionalismo y la causalidad para vivir un proceso de inmersión a través de la cognición comunicativa interpretativa que los saque del uso y los involucre en la apropiación, y finalmente para que cuando adelanten sus actividades académicas 0 construyan proyectos, sus procesamientos de información y conocimientos se centren en la apropiación profunda de los conceptos y los contextos.

Echeverri (2006) resalta que "Tres elementos del mundo contemporáneo se distinguen como potencias para enfrentar los retos del siglo XXI: tecnología, comunicación y educación, los tres inextricablemente relacionados hacen parte de las preocupaciones del poder-saber actual" (p.1). Es necesario que el campo de los Comunicadores Sociales maximice su cognición comunicativa interpretativa para que conceptualicen y contextualicen desde la triada tecnología - comunicación - educación. Esto se debe abordar con el objetivo de que aprehendan a desentrañar las producciones y realizaciones mediáticas (masivas (tradicionales y nuevas), académicas y personales), pero también a intrincar las producciones y realizaciones mediáticas (académicas, profesionales y personales) de manera responsable y comprometida, tanto en lo cultural, social, político y económico.

Es primordial tener en cuenta que los elementos y componentes de los ambientes virtuales difieren de la formación presencial, ya que el nuevo peso radica en las estrategias y acciones tecnológicas, comunicativas y educativas en interacción auditiva y visual. Según Lima (2005), “(...) se reconoce que las tecnologías constituyen instancias mediadoras del aprendizaje (son los lugares donde se propicia, dificulta o frustra el aprendizaje) al igual que el grupo, la institución, el contexto, el maestro y uno mismo, y que, toda mediación constituye un modelo integrador (p.6). Por lo tanto, es necesario considerar que los medios en el aula virtual no deben ser vistos como apoyo, acompañamiento, ilustración, entretenimiento, naturalización, etc., sino darles el valor pedagógico como parte de la enseñanza aprendizaje. Lima (2005) expresa que "[...] se extiende el criterio de la necesidad de crear Nuevos Ambientes de Aprendizaje, con recursos tecnológicos de punta y de "no punta" que faciliten diseñar situaciones educativas cuyo centro sean los alumnos, su actividad y la comunicación, no importa que estén; presentes y/o a distancia" (p.6). Es decir, que se logren integrar profundamente y conyunturalmente los elementos y componentes que van desde los signos hasta las narrativas mediáticas pedagógicas que los estudiantes deben aprehender a aprehender para poder alcanzar interpretaciones pertinentes.

La investigación expuesta en este manuscrito lleva a proponer nuevas preguntas desde la Cognición comunicativa interpretativa relacionadas ahora con la educación virtual:

¿La triada tecnología - comunicación - educación está contribuyendo en las aulas virtuales a la formación de calidad de los estudiantes universitarios? ¿Los diseños auditivos y visuales de los temas de los 
programas universitarios están logrando detonar el aprehender en las aulas virtuales? ¿A los estudiantes universitarios se les facilita, dificulta o frustra el aprehender con la aplicación actual de la triada tecnología comunicación - educación? ¿Los estudiantes universitarios son competentes para aprehender con las narrativas auditivas y visuales que se les comparten en las aulas virtuales? ¿Los universitarios son formados en semiótica mediática del texto - imagen para interpretar los recursos documentales y audiovisuales de las aulas visuales? ¿Se está formando a los universitarios en la decodificación y codificación de las narrativas mediáticas desde lo técnico hasta lo simbólico? ¿Mediáticamente los universitarios son competentes para aplicar sus conocimientos académicos y profesionales en el mundo de las tecnologías de las informaciones y las comunicaciones? ¿Por qué se continúa insistiendo por parte de las universidades procesos y procedimientos de formación con base en el texto si los universitarios viven en el mundo audiovisual? ¿Los universitarios han sido consultados sobre cómo podría desarrollarse una tutoría virtual o una clase presencial con componente virtual o se continuará con la posición de poder del sistema educativo?, entre otros cuestionamientos.

El problema investigado permitió detectar dos limitaciones en los informantes: la primera, el desconocimiento de los profesores sobre la conceptualización del entender, el comprender y el interpretar, sobre los cuales construyeron discursos con poco sustento. La segunda, el desconocimiento conceptual generó resistencia frente a la problemática, ya que solo uno de ellos, por su disciplina la consideró trascendental y como aporte a su conocimiento, porque el resto de los docentes estaban acordes con la forma como aprendían los estudiantes.

Formar con calidad debe ser el principal propósito de los programas de Comunicación
Social por lo cual precisamente se realizó la investigación que generó este manuscrito y desde ya se propone su continuidad. Chapa y Martínez (2016), argumentan que "Una de las tendencias en la educación superior es formar universitarios que superen todas las expectativas que los llevaron a la decisión de ingresar a estudiar una determinada profesión, en donde adquieran conocimientos, alcancen resultados que den soluciones a los problemas o busquen alternativas en la investigación, para la innovación y competitividad, [...]" (p.3). Los programas de Comunicación Social tienen claro su involucramiento con el mundo de las informaciones y de los conocimientos mediáticos, por lo tanto, esta situación demanda mejorar sus competencias de interpretación de textos e imágenes, para que sean más competitivos en los lugares y no lugares laborales donde se desempeñen.

\section{REFERENCIAS}

Acevedo, S., Martínez, L. y Román, I. (2014). Revisión de los procesos de comprensión y producción de textos académicos en el ámbito de la educación superior presencial y virtual. Revista de Investigaciones UNAD, 13(2).

https://tinyurl.com/yxsqm2ga

Alexopoulou, A. (2010). Tipología textual y comprensión lectora en E/LE. Revista Nebrija de Lingüística Aplicada a la Enseñanza de las Lenguas, (9).

https://www.nebrija.com/revistalinguistica/tipologia-textual-ycomprension-lectora-en-e-le.html

Almaguer L. B. y Peña G. R. (2009). La lectura y las diferencias entre entender, comprender e interpretar. La Lectura, 13. 
http://aal.idoneos.com/revista/ano_11_ nro._13/entender,__ comprender_e_ interpretar/

Bruner, J. S. (2008). Culture and Mind: Their Fruitful Incommensurability. Ethos, 36(1), 29-45.

https://anthrosource.onlinelibrary.wiley.com/doi/ abs/10.1111/j.1548-1352.2008.00002.x

Cassany, D. (2004). Explorando las necesidades actuales de comprensión: aproximaciones a la comprensión crítica. Repositorio de la Universidad Pompeu Fabra, 25(2), 6-23.

https://repositori.upf.edu/bitstream/ handle/10230/21237/Cassany_LyV_2. pdf?sequence $=1$ \&isAllowed $=y$

Cassany, D. (2010). 10 Claves para aprender a interpretar en Ministerio de Educación, Con firma 2010, Leer para aprender. Leer en la era digital (pp. 191-195). Portal leer.es.

https://www.researchgate.net/ publication/292407047_10_claves_ para_aprender_a_interpretar

Chapa, A. P. y Martínez C. T de J. (2016). La importancia de la actualización de conocimientos como parte de la formación del docente universitario. Iberoamericana de Producción Académica y Gestión Educativa, (4).

https://www.pag.org.mx/index.php/PAG/ article/view/420

Echeverry, A. J. (2006). Historicidad de la tríada tecnología, comunicación y educación. Educación, Comunicación, Tecnología, 1(1), 1- 20.
Escobar, C. A. (2016). El lenguaje como imagen/la imagen como lenguaje [Tesis Licenciatura, Universidad de Chile].

http://repositorio.uchile.cl/bitstream/ handle/2250/137634/El-lenguaje-comoimagen-la-imagen-como-lenguaje. pdf?sequence $=1$

Filmus, D. (2003). Breves reflexiones sobre la escuela del futuro y presentación de la experiencia "Aulas en red" en $\mathrm{O}$. E. González Pérez, M. Díaz Pinto, C. Alvariño, M. Zúñiga, I. Jara, E. García, Educación y Nuevas Tecnologías. Experiencias en América Latina ( $p p$. 15-33). Instituto Internacional de Planeamiento de la Educación IIPEUnesco.

Gordillo, A. A. y Flórez, M del P. (2009). Los niveles de comprensión lectora: hacia una enunciación investigativa y reflexiva para mejorar la comprensión lectora en estudiantes universitarios. Actualidades Pedagógicas, 53, 95-107.

Macías, M. A. (2002). Las múltiples inteligencias. Psicología desde el Caribe, (10), 27-38. https:// www.redalyc.org/ pdf/213/21301003.pdf

Martínez, R. L. (2007). La observación y el diario de campo en la definición de un tema de investigación. Los Libertadores, 77-80.

https://www.ugel01.gob.pe/wpcontent/uploads/2019/01/1-LaObservaci\%C3\%B3n-y-el-Diario-decampo-07-01-19.pdf

Pantoja, Ch. A. (2008). La imagen como escritura. El discurso visual para la historia. Norba, 20, 185- 208. https:// tinyurl.com/y4cn3kax 
Peñalver, M. (2008). Las perplejidades del lector contemporáneo: semiotizar, interpretar, deconstruir. Fragmentos de filosofía, (3), 129-156.

http://institucional.us.es/revistas/ fragmentos/3/ ART\%208.pdf

Pirela, M. J. y Montiel, S. L. (2007). La acción comunicativa-cognitiva y el proceso de construcción de la arquitectura mental en la cibersociedad. Utopía y Praxis Latinoamericana, 12(39), 73- 84.

http://www.scielo.org.ve/scielo. php?script=sci_arttext\&pid $=$ S1315-52162007000400005

Sartori, G. (2000). Homo videns. La sociedad teledirigida. Taurus.

Salamanca, C. A y Martín-Crespo, B. (2007). El muestreo en la investigación cualitativa. Nure Investigación, (27).

Significados. (s.f). Cognición. https://www. significados.com/cognicion/

Schunk, D. H. (1997). Teorías del aprendizaje. Industrial Atoto.

Strauss, A. y Corbin, J. (2002). Bases de la investigación cualitativa. Técnicas y procedimientos para desarrollar la teoría fundamentada. Editorial Universidad de Antioquia.

Van Dijk, T. A. (1994). Análisis del discurso.

http://acreditacion.unillanos.edu.co/ CapDocentes/ contenidos

Van Dijk, T. A. (2000). La noticia como discurso. Comprensión, estructura y producción de la información. Paidós Comunicaciones.
Yuste, F, J. (2011). Leer e interpretar la imagen para traducir. Campinas, 50(2).

http://dx.doi.org/10.1590/S010318132011000200003 org/10.1590/ S0103-18132011000200003 